\title{
Comparison of thermal comfort in a traditional and intelligent building
}

\author{
Natalia Krawczyk ${ }^{1 *}$, \\ ${ }^{1}$ Faculty of Environmental, Geomatic and Energy Engineering, Kielce University of Technology, Poland
}

\begin{abstract}
The article presents a comparison of thermal comfort in two educational buildings of the Kielce University of Technology, a traditional building and an intelligent building Energis (using solar energy to generate electricity for heating water and lighting the building). The results obtained from the questionnaires allowed the calculation of the Thermal Sensation Vote (TSV) and comparison with the Fanger model. The analysis consisted in comparing the thermal and air humidity ratings in both buildings. Graphs on thermal assessment, air humidity and thermal preferences were drawn up. On the basis of the obtained results, it can be concluded that the vast majority of the respondents did not feel well in the rooms they studied. The results obtained from the research may be useful for building managers to apply the appropriate thermal conditions.
\end{abstract}

\section{Introduction}

Nowadays (Covid - 19) our way of living and working has changed to remote mode like never before. We spend more and more time indoors. Therefore, the aspect of thermal comfort is becoming more and more common. Each of us, while working or learning, wants to be provided with the right conditions for work or study. Thermal comfort is characterized by the fact that we feel comfortable in given climatic conditions. Adequate thermal conditions in existing and modern buildings must be guaranteed, in which we are neither too warm nor too cold. A person feels comfort in different ways. One person may feel warm under the same conditions and the other cold. Therefore, adjust the room climate to suit the majority. Failure to provide appropriate conditions has a negative effect on our body. Human organisms have different biological characteristics, which is associated with different feelings when staying in the same conditions. The temperature regulating system controlled by the thermal center is responsible for the balance of our body. Failure to provide the right climatic conditions can affect our productivity, health, fatigue and well-being. In order to ensure thermal comfort, people staying in the room at the moment should be kept in an appropriate state of air. The feeling of thermal comfort also affects our performance. That is why thermal comfort is such an important aspect.

In order to determine the appropriate thermal comfort, it is reasonable to consider as many factors as possible that affect the thermal sensation of a person. The main parameters that influence the determination of thermal comfort are: air temperature and velocity, average radiation temperature, relative humidity and physical activity. In the 1970s, a thermal comfort model was developed by O. Fanger based on ISO 7730 [1] and PN-EN 16798-1: 2019 [2]. In the thermal comfort equation developed by Fanger on the basis of his own research and related literature, 16 elements describing the environment and man are taken into account. He determined the PMV (Predicted Mean Vote), PPD (Predicted Percentage of Dissatisfied) index and plotted the thermal comfort graph, which is a function of physical activity, thermal insulation of clothing, temperature, air humidity, and the average ambient radiation temperature [3-5]. The topic of thermal comfort is becoming more and more interesting. The authors [6] carried out research in residential buildings. They examined 205 apartments in summer and 189 in winter. Their results showed that PMV was below zero in summer and the other way around in winter. They found that the results of the PMV calculations differ significantly from the results of the questionnaire surveys. Jazizadeh et al. [7] stated in the research on thermal comfort that air temperature is the most important factor influencing thermal comfort. The authors [8] showed that the thermal sensations were most influenced by air temperature and humidity. Bartal et al. [9] in the article showed the essence of thermal comfort using the Fanger model. They presented a statistical heat balance of the human body and heat loss through sweating. They also showed how the graph of thermal comfort changes for lightly clothed people at different levels of activity. Enescu [10] discussed a thermal comfort model for predicting relevant variables, including air temperature and PMV. Broday et al. [11] compared the results of thermal comfort based on the Fanger model with the results based on the questionnaires. On the other hand, the authors [12] showed in the research that it is possible to provide room users with thermal comfort and thus reduce operating

\footnotetext{
*Corresponding author: nkrawczyk@ tu.kielce.pl
} 
costs with the use of renewable energy sources. Vilcekova et al. [13] presented the differences between the PMV results and the actual feelings from the questionnaires. The authors showed similar results $[14,15]$. In Poland, however, the authors were involved in research on thermal comfort [16-19]. Based on the presented literature review, it should be noted that there is no generally acceptable model of thermal comfort.

The article presents a comparison between the traditional $\mathrm{D}$ building and the Energis intelligent building of the Kielce University of Technology. The actual results and the questionnaires were compared with the Fanger model.

\section{Material and method}

The research was carried out in June 2021 in the traditional D and intelligent building Energis of the Kielce University of Technology. The modern building has mechanical ventilation, in which it is possible to control the ventilation. It is equipped with heat pumps, solar collectors and photovoltaic cells. Thanks to them, the building is self-sufficient and uses renewable energy sources. Below is a photo of the Traditional and Intelligent Building from the Eastern side.

a)

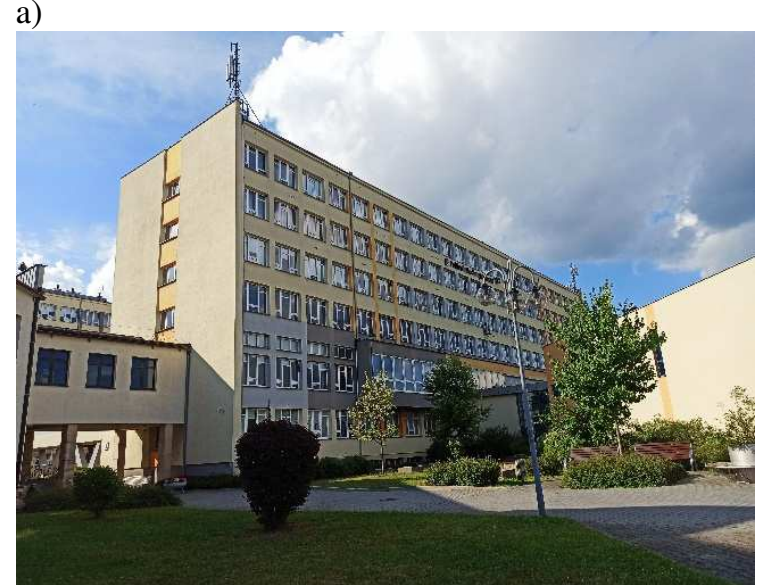

b)

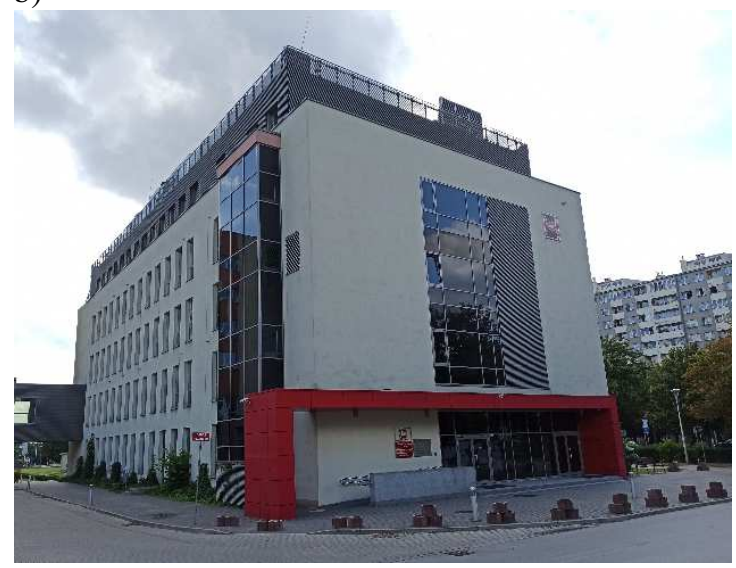

Fig. 1. Photos of the Traditional (a) and Intelligent (b) Building.

During the tests, ventilation was not turned on in both rooms. During the tests, air was exchanged through tilted windows and doors. The study was based on two methods. The first method was to measure the air parameters with a Testo 400 microclimate meter. The following parameters were measured: air temperature and velocity, relative humidity, black ball temperature and carbon dioxide. The values indicated by the measuring tools were read after the measurements had stabilized for 15 minutes. Table 1 below shows the air parameters for the buildings in question.

Table 1. Air parameters in the tested buildings.

\begin{tabular}{|c|c|c|}
\hline & $\begin{array}{c}\text { Traditional } \\
\text { building }\end{array}$ & $\begin{array}{c}\text { Intelligent } \\
\text { building } \\
\text { Energis }\end{array}$ \\
\hline $\begin{array}{c}\text { Air } \\
\text { temperature, } \\
{ }^{\circ} \mathrm{C}\end{array}$ & 27.50 & 26.70 \\
\hline $\begin{array}{c}\text { Air speed, } \\
\mathrm{m} / \mathrm{s}\end{array}$ & 0.05 & 0.09 \\
\hline $\begin{array}{c}\text { Air } \\
\text { humidity, \% }\end{array}$ & 50.92 & 47.10 \\
\hline $\begin{array}{c}\text { Black ball } \\
\text { temperature, } \\
{ }^{\circ} \mathrm{C}\end{array}$ & 27.80 & 26.50 \\
\hline $\begin{array}{c}\text { Carbon } \\
\text { dioxide, } \\
\text { ppm }\end{array}$ & 580 & 695 \\
\hline
\end{tabular}

The second method, on the other hand, consisted in completing the questionnaires by students, which concerned the thermal impressions of the microclimate in which they were. This study allowed for the assessment of thermal comfort, as well as their preferences as to the prevailing conditions in the room. A photo of the test stand is shown below (Fig. 2).

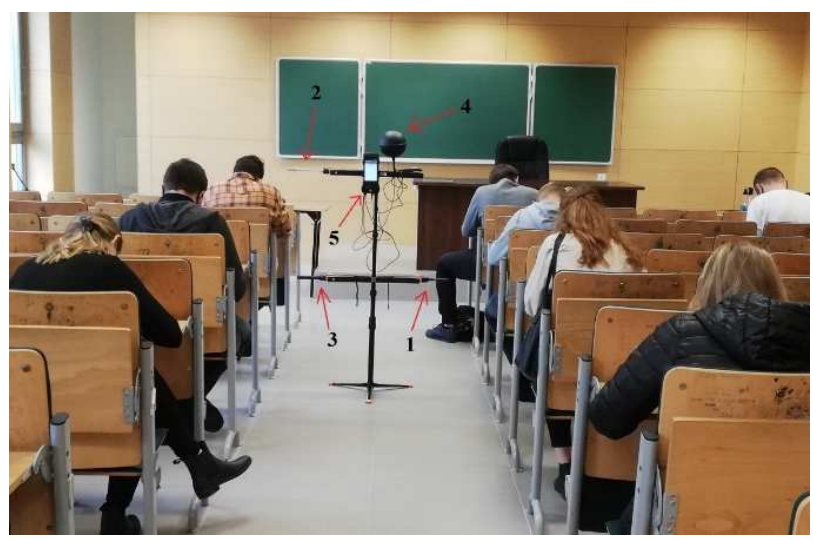

Fig. 2. Photo of the test stand with the Testo 400 microclimate measuring device in the test room.

The Testo 400 meter collected information about the microclimate conditions in the room from probes mounted on a tripod. The air temperature measurement was measured with an accuracy of $+/-0.3^{\circ} \mathrm{C}$, and the relative humidity was $+/-2 \%$. In Figure 2, the probe for measuring the above-mentioned parameters is marked with " 1 ". The air velocity was measured with a special probe (marked "2" in Figure 2) with an accuracy of $+/$ $0.03 \mathrm{~m} / \mathrm{s}$. $\mathrm{CO}_{2}$ concentration was carried out using probe " 3 ". The measurement error is $+/-50 \mathrm{ppm}$. The " 4 " probe marked in Fig. 2 was used to measure the average 
radiation temperature with an accuracy of $+/-0.3^{\circ} \mathrm{C}$. All probes were connected to the multifunction meter (" 5 " is marked in Fig. 2).

\section{Results and discussion}

The measurements were made in June this year. 32 people aged 22-32, including 5 women and 27 men, participated in the study. In the traditional room, which is lecture hall 1.10, located on the first floor in building. Lecture hall 1.09 in an intelligent building is also located on the first floor. During the tests, windows and doors were ajar in the rooms. During the tests, ventilation was turned off. Figure 3 below presents the percentage of the obtained responses regarding thermal sensations.

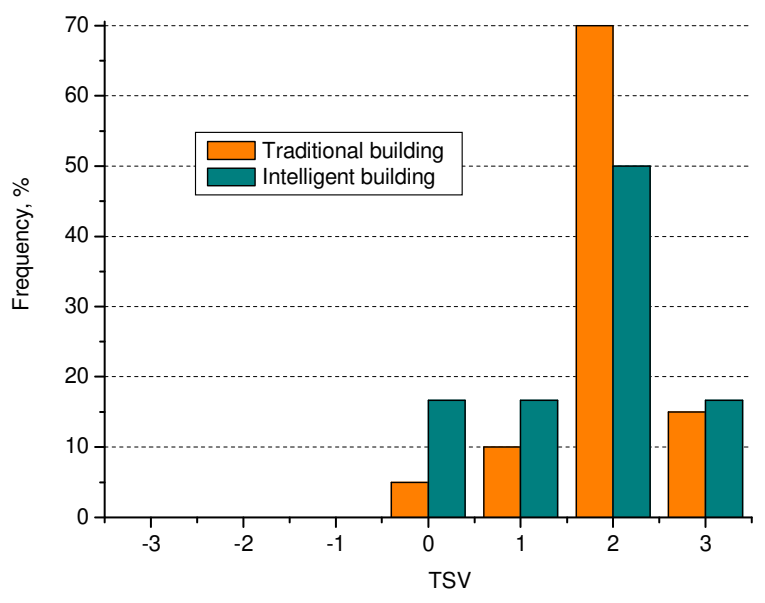

Fig. 3. Thermal sensations vote (TSV) based on questionnaires: "-3" - too cold, "-2" - too cool, “-1" - pleasantly cool, "0" - comfortable, "1" - pleasantly warm, "2" - too warm, "3" - too hot.

The chart shows the results of the thermal feeling surveys. When asked about thermal sensations, the vast majority chose the answer "too warm". For a traditional building, this answer was $70 \%$, i.e. 14 out of 20 people chose this answer. And for an intelligent building, 6 people out of 12 , which is $50 \%$. The second most frequently chosen option for a traditional building was the answer "too hot" and it amounted to $15 \%$. The answer "pleasantly warm" was repeated twice, which is $10 \%$. The least answer given was "comfortable" and it was $5 \%$, which means that one person out of 20 was comfortable. Looking at the answers for intelligent building, you can see that "comfortable", "pleasantly warm" and "too hot" are on the same level. So 2 respondents out of 12 chose individual options and they amounted to $16.67 \%$ each. During the study, ventilation was turned off (air temperature $-26.70^{\circ} \mathrm{C}$ ), therefore the respondents did not feel comfortable in the tested room. Moreover, for an intelligent building, the number of people surveyed is too small to explain why only two people chose the answer "comfortable". They probably feel comfortable with the higher temperature conditions. When comparing all the answers for both buildings, it was noticed that the respondents did not feel well in the rooms studied. It can be concluded that there was no thermal comfort in the buildings. This is confirmed by the fact that the percentage of selecting "3 ", "-2", "2" and "3" was greater than $10 \%$. It amounted to $78.13 \%$ for the entire group. However, for individual buildings it looks like this. For the traditional building it was $85 \%$, and for the intelligent building $66.67 \%$. This may be due to the season (summer) with high air temperatures. The following figure shows the effect of BMI on the thermal sensation vote.

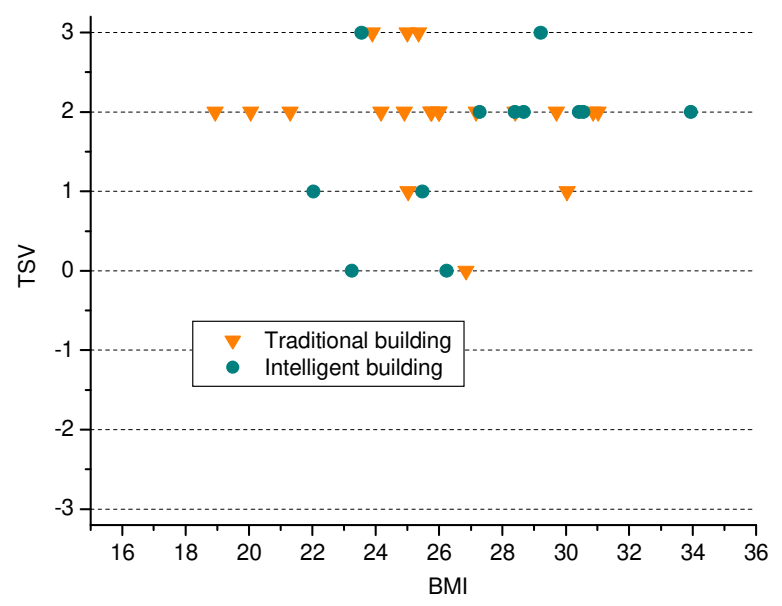

Fig. 4. Dependence of TSV on the BMI mass index for traditional and intelligent building.

The chart above shows the dependence of the thermal sensation vote on the calculated BMI (Body Mass Index). BMI is calculated by dividing your weight (in kilograms) by your height squared (in meters). The BMI index was compared with thermal voices. It has been noticed that people with an index above 26 have a higher thermal sensation and prefer a lower temperature. More than half of all respondents clearly stated that they are too warm (20 out of 32). The study also shows the percentage of temperature (Fig. 5).

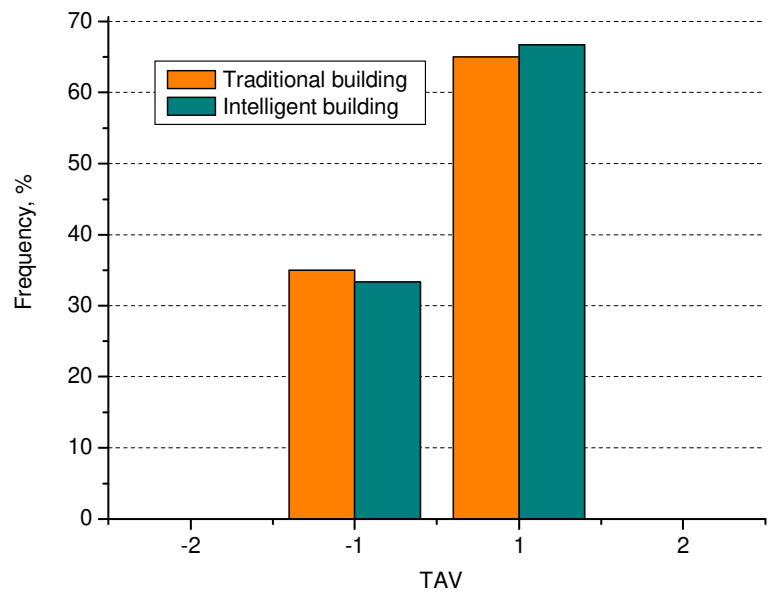

Fig. 5. Thermal acceptability vote (TAV) based on questionnaires: "-2" - definitely unpleasant, “-1" - unpleasant, "1" - acceptable, "2" - comfortable.

In general, according to the survey results for both facilities, it appears that people inside the rooms are satisfied with the microclimate conditions. In the 
traditional building, 13 out of 20 respondents chose the answer "acceptable", which is $65 \%$. Seven people rate the air temperature as already unacceptable " -1 ", or $35 \%$. The air assessed by respondents from intelligent building is as follows: 8 people out of 12, i.e. $66.67 \%$ rated it as "acceptable", while the others (i.e. 4 people) as "unpleasant" $(33.33 \%)$. The advantage of an intelligent building compared to a traditional building in terms of the answer "acceptable" is shown in Figure 3, where for an intelligent building there are many more " 0 " - comfortable and " 1 " answers - pleasantly warm. In contrast, in the traditional one, the answers regarding dissatisfaction " 2 " prevail. Figure 6 shows the expectations for air temperatures.

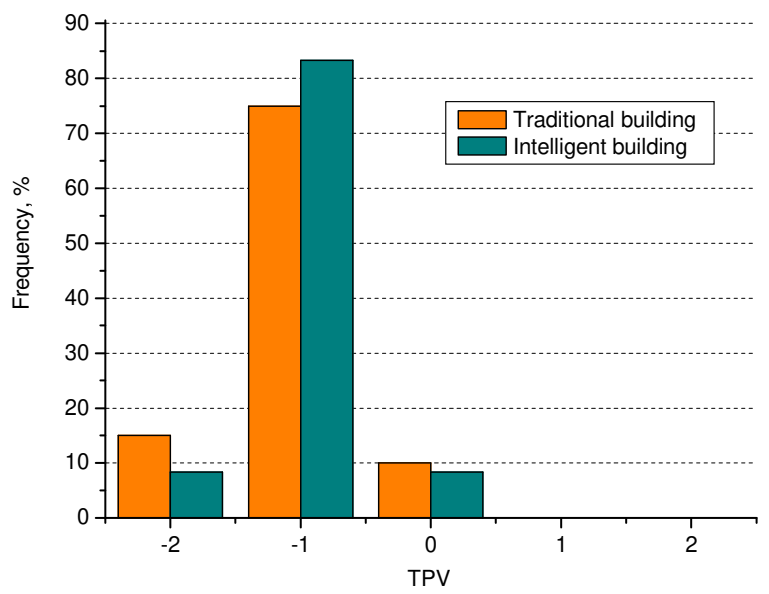

Fig. 6. Thermal preferences vote (TPV) based on questionnaires: "- 2 " - definitely cooler, "-1" - cooler, "0" - unchanged, "1" - warmer, "2" - definitely warmer.

Of the respondents' answers for a traditional room, the most frequently given answer was "cooler". 15 out of 20 students want the room to be cooler, i.e. $75 \%$. Three people wanted "definitely cooler" $(15 \%)$ and two people chose "unchanged" - 10\%. For an intelligent building, the vast majority, as many as $83.33 \%$, believed that the temperature in the room should be cooler. Only one person, or $8.33 \%$, would like the room temperature to remain the same. One student also chose "definitely cooler". The next graph (fig. 7) shows the comparison of PMV (Predicted Mean Vote) and TSV (Thermal Sensations Vote).

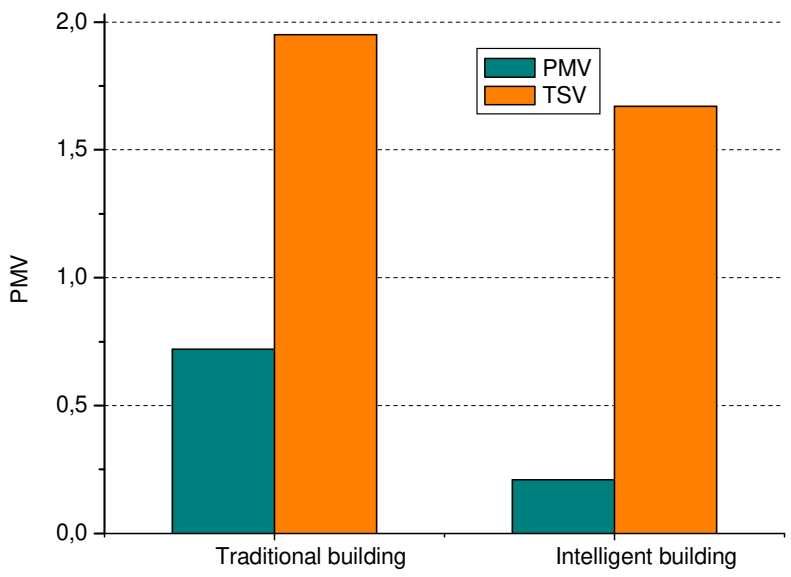

Fig. 7. Comparison of the average thermal comfort rating from the questionnaires and the Fanger model.

Figure 7 shows the confrontation of the results of the average assessment of thermal comfort obtained using the Fanger model (PMV) with the results calculated on the basis of the questionnaires (TSV). Based on the graph, it can be concluded that the Fanger model significantly underestimates the TSV results. The discrepancy between the two values may depend on many factors not taken into account in the Fanger's model. Both in building and building Energis these differences are significant. They amount to 1.23 for a traditional building, and 1.46 for an intelligent building. This difference may be due to the fact that the model does not take into account other parameters that may affect people's feelings and their answers in the questionnaires (e.g. $\mathrm{CO}_{2}$ concentration or the location of the room and windows in relation to the directions of the world). The next figure presents the respondents' answers regarding the assessment of humidity.

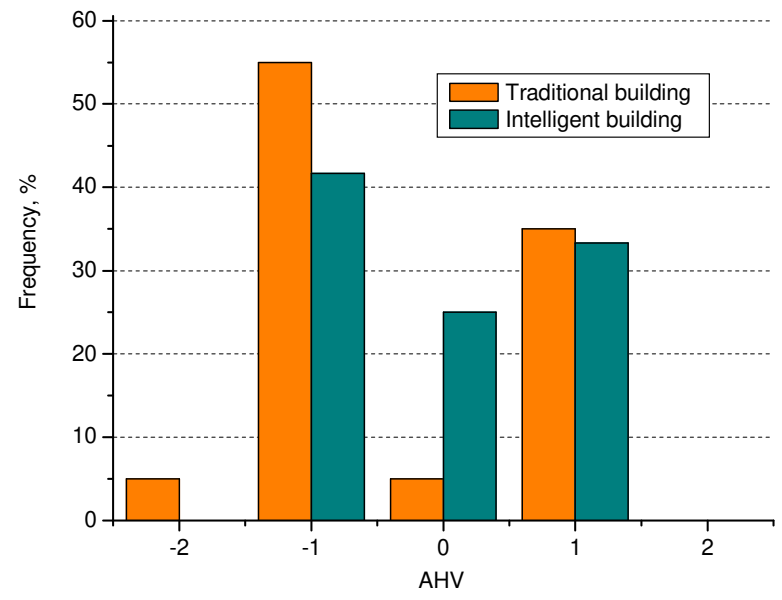

Fig. 8. Air humidity vote (AHV) based on questionnaires: "-2" - too dry, "-1" - fairly dry, "0" - pleasantly, "1" - quite damp, "2" - too humid.

The chart above shows the respondents' assessment of air humidity in the rooms in which they were located. At first glance, you can see the similarities in the voting of the respondents. Most votes were cast for the answer, "fairly dry". In both rooms, the respondents exceeded $40 \%$. Respectively for the D building - 55\% and the Energis building - $41.67 \%$. Most common features can be seen with the answer "quite damp". The result for both buildings fluctuated around 35\%. The biggest discrepancy is for the answer "pleasantly". As many as $25 \%$ of respondents feel comfortable in the Energis building in terms of humidity, unfortunately only $5 \%$ gave this answer in building. Both the answers "too dry" and "too humid" were usually omitted in both buildings. Only in building the answer "too dry" was voted by $5 \%$ of the respondents. The research also showed preferences for humidity. 


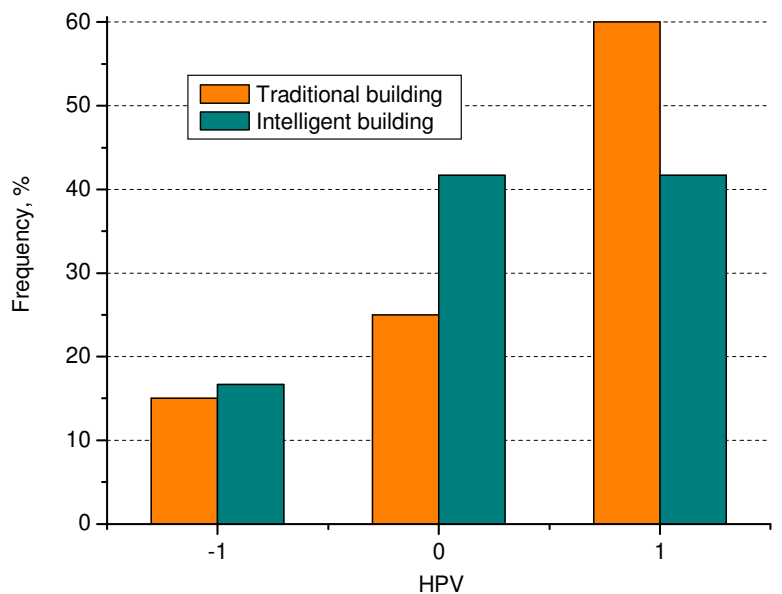

Fig. 9. Assessment of humidity preferences vote (HPV) based on questionnaires: "-1" - more dry, "0" - no change, "1" - more humid.

Chart 9 shows the preferences of the respondents with regard to indoor air humidity. Both in the traditional D building and in the Energis building, the respondents want changes. It is most visible on the example of building. In it, the majority of the respondents, $60 \%$, voted for "more humid". Much fewer votes for "more dry" - $15 \%$. Only every 4th person $-25 \%$ in building did not want to change. The respondents in the Energis building voted slightly differently. More than $41.67 \%$ of the votes were cast for the answer "no change", but this is not an indicator of the comfort in the room, as the same number of votes were cast for "more humid". The fewest votes were cast for "more dry", i.e. $16.67 \%$.

\section{Conclusion}

The above results show a significant discrepancy between the Fanger model (PMV) and the statistical responses of the subjects (TSV). These tests were carried out in two different buildings, where ventilation was turned off during the tests. When analysing the results for the Fanger model for both buildings, significant discrepancies were noticed between the values calculated using the Fanger formula and the average of the respondents' answers (1.23 for the traditional one, 1.46 for the intelligent one). Both buildings had similar air parameters. It is also worth noting that the respondents did not feel well indoors (over $78 \%$ of all people were dissatisfied). This proves that the Fanger model is insufficient today. Its assumptions are more consistent with those expected in buildings with traditional ventilation, and this type is more and more often replaced by the intelligent ventilation type.

In terms of humidity, definitely more people felt comfortable in an intelligent building than in a traditional one. There are also differences for the TSV. Almost $17 \%$ of respondents felt comfortable in an intelligent building, and only $5 \%$ in a traditional building. PPD (Predicted Percentage of Dissatisfied) for the respondents is as follows: intelligent building $66.67 \%$, traditional building - $85 \%$. It may probably be due to the fact that the intelligent building has greater wall insulation, which is why the respondents felt better in this building.

The model for calculating thermal comfort requires updating and adapting it to the current trends in architecture. The presented research will be continued in order to collect more data for thermal comfort.

\section{References}

1. ISO International Organisation for Standardization, Ergonomics of the thermal environment Analytical determination and interpretation of thermal comfort using calculation of the PMV and PPD indices and local thermal comfort criteria, International Standard ISO 7730, (2005)

2. PN-EN 16798-1:2019, Energy Performance of Buildings-Ventilation for Buildings-Part 1: Indoor Environmental Input Parameters for Design and Assessment of Energy Performance of Buildings Addressing Indoor Air Quality, Thermal Environment, Lighting and Acustics (2019)

3. P.O. Fanger, Calculations of thermal comfort: introduction of a basic comfort equation. ASHRAE Transactions 73, 1-4 (1967)

4. P.O. Fanger P.O. Komfort cieplny, tł. doc. dr inż. K. Kostyrko, dr A. Kostryko, Arkady, Warszawa (1974)

5. P.O. Fanger, Thermal comfort - analysis and applications in environmental engineering. Danish Technical Press, Copenhagen (1970)

6. R. Becker, M. Paciuk, BaE 44, 948 - 960 (2009) http://dx.doi.org/10.1016/j.buildenv.2008.06.011

7. F. Jazizadeh, F.M. Marin, B. Becerik-Gerber, BaE 68, 1440-149 (2013) http://dx.doi.org/10.1016/j.buildenv.2013.06.011

8. R.Z. Homoda, K.S.H. Saharia, H.A.F. Almurib, F.H. Nagi, BaE 49, $141 \quad-153$ (2012) https://dx.doi.org/10.1016/j.buildenv.2011.09.012

9. I. Bartal, L. Banhidi Hc., L. Garbai, EaB, Department of Building Service Engineering and Process Engineering, Budapest University of Technology and Economics, Muegyetem" rkp. 3, Hungary https://dx.doi.org/10.1016/j.enbuild.2012.02.005

10. D. Enescu, Valahia University of Targoviste, RaSER 13, 1353-1379 http://dx.doi.org/10.1016/j.rser.2017.05.175

11. E.E. Broday, J.A. Moret, Antonio Augusto de Paula Xavier, Reginaldo de Oliveira, International Journal of Industrial Ergonomics 69, 1 - 8 (2019) https://doi.org/10.1016/j.ergon.2018.09.007

12. X. Xu, W. Hu, W. Liu, Y. Du, R. Huang, Q. Huang, Zhe Chen, EC\&M 230 (2021) https://doi.org/10.1016/j.enconman.2021.113831

13. S. Vilcekova, L. Meciarova, E.K. Burdova, J. Katunska, D. Kosicanova, S. Doroudiani, BaE 120, 
$29 \quad-\quad 40 \quad$ (2017)

http://dx.doi.org/10.1016/j.buildenv.2017.05.001

14. S.T. Mors, J.L.M. Hensen, M.G.L.C. Loomans, A.C. Boerstra, BaE 46, 2454 - 2461 (2011) https://doi.org/10.1016/j.buildenv.2011.05.025

15. S. Manu, Y. Shukla, R. Rawal, L.E. Thomas, de Dear R., BaE 98, $55 \quad$ - $70 \quad$ (2016) https://doi.org/10.1016/j.buildenv.2015.12.019

16. G. Majewski, M. Telejko, Ł.J. Orman, (EKODOK), Poland, E3S Web of Conferences, 17, 00056, (2017) https://doi.org/10.1051/e3sconf/20171700056

17. J.Zb. Piotrowski, Ł.J. Orman, X. Lucas, E. Zender - Świercz, M. Telejko, D. Koruba, Czech Republic, EPJ Web of Conferences, 67, 02095, (2014) https://doi.org/10.1051/epjconf/20146702095

18. N. Krawczyk, 20-21 April 2021, Tallinn, Estonia (2021) https://doi.org/10.1051/e3sconf/202124615003

19. L. Dębska, J. Krakowiak, 20-21 April 2021, Tallinn, Estonia https://doi.org/10.1051/e3sconf/202128004011 